\title{
Interpersonal correlates of the tendency to seek help in the situation of indebtedness in healthy people and in patients with impaired mobility, related to chronic disorders of the locomotor system - Pilot study
}

\author{
Anna Mazur ${ }^{1, A-F} \oplus$, Tomasz Saran ${ }^{1, A-F}{ }^{\oplus}$, Jacek tukasiewicz $^{2, A-F}{ }^{\oplus}$, Marcin Stencel $^{2, A-B, D-E} \oplus$, \\ Adam Raczkowski ${ }^{2, A-E \oplus}$, Andrzej Cwynar ${ }^{2, E-F} \oplus$, Wiktor Cwynar ${ }^{2, E-F} \odot$ \\ ${ }^{1}$ Department of General and Neuro Rehabilitation, Witold Chodźko Institute of Rural Health, Lublin, Poland \\ ${ }^{2}$ University of Economics and Innovation, Lublin, Poland \\ A - Research concept and design, B - Collection and/or assembly of data, C - Data analysis and interpretation, \\ $D$ - Writing the article, E - Critical revision of the article, F - Final approval of article.
}

\begin{abstract}
Mazur A, Saran T, Łukasiewicz J, Stencel M, Raczkowski A, Cwynar A, Cwynar W. Interpersonal correlates of the tendency to seek help in the situation of indebtedness in healthy people and in patients with impaired mobility, related to chronic disorders of the locomotor system Pilot study. Ann Agric Environ Med. 2019; 26(4): 630-635. doi: 10.26444/aaem/102493
\end{abstract}

\begin{abstract}
Introduction. The way of functioning in everyday life and the style of coping with the challenges encountered, including the situations of financial difficulties, are shaped by various adaptation mechanisms conditioned by the state of psychophysical health, as well as social and cultural factors. They are related to the intrapsychic features, among which the personality plays a key role.

Materials and method. The research sample consisted of 2 groups - 50 patients with mobility impairment resulting from chronic pathologies of the locomotor system hospitalized in the Department of General and Neuro Rehabilitation, Institute of Rural Health in Lublin, and 50 healthy people. The research was carried out using the NEO-FFI Personality Inventory, Perceived Stress Scale, Self-Esteem Scale, General Self-Efficacy Scale, Impulsiveness Inventory and the APSZ Questionnaire. Results. In the group of patients with impaired mobility resulting from chronic pathologies of the locomotor system, the leading correlate of the tendency to seek help in the situation of indebtedness was extraversion. In the healthy group, the leading correlates of the tendency to undertake this type of activity were the intensity of perceived stress, neuroticism, self-esteem, self- efficacy and empathy.

Conclusions. In the group of patients with impaired mobility resulting from chronic diseases of the locomotor system, extroversion was the factor conducive to seeking help in the situation of indebtedness. In the group of healthy people, self-esteem, self- efficacy and empathy were the factors conducive to taking such actions, whereas intensity of perceived stress and neuroticism were the risk factors.
\end{abstract}

\section{Key words}

debt, intrapersonal functioning, seeking help, mobility impairment, chronic disorders of the locomotor system, healthy persons

\section{INTRODUCTION}

Degenerative joint disease (osteoarthritis) is the most common cause of age-related motor restrictions. Osteoarthritis is an invasive disease conditioned by a natural, individually varied degeneration and loss of the amount of articular cartilage. Over time, the cartilage loss leads to changes in the neighbouring bone area and peri-articular structures, such as articular ligaments and muscles [1-3]. At the same time, osteoarthritis is closely related to the mechanical wear of joints, overloads in everyday life and work, obesity and metabolic disorders, such as diabetes. Systemic metabolic diseases often accelerate damage to the entire joint structure and periarticular tissues. The course of disability associated

Address for correspondence: Jacek Łukasiewicz, University of Economics and Innovation in Lublin, Poland

e-mail: jlukasiewicz@scj.pl

Received: 05.10.2018; accepted: 03.01.2019; first published: 13.02.2019 with osteoarthritis varies individually and depends on genetic factors, lifestyle and work environment. The disease initially causes low-grade pain; however, after many years it leads to chronic suffering, disability and social and professional exclusion. Patients with osteoarthritis have clearly limited daily activity, which leads to further muscle weakness, weakness of joint structures and, as a result, acceleration of disability $[4,5]$.

Physical limitations cause changes in mental functioning resulting from chronic pain and disability [6]. Another important reason for mobility disability concerning slightly younger people, is a spinal pain. As in the case of arthrosis of peripheral joints, in the pathology of spinal pain syndrome and its destruction, the genetically determined phenomenon of the weakening of structures, mainly intervertebral discs and intervertebral joints, is important. Overloading plays an even more important role in this case than in arthrosis of peripheral joints. In the initial phase of the disease, a 
significant role is played by chronic psychological stress as a factor triggering increased paraspinal muscle tone. The lumbosacral spine pain syndrome is a health problem with very high prevalence [7-9].

Epidemiological statistics conducted in the United States indicate that about $75-85 \%$ of the population feel or suffer from such ailments, and the annual incidence is about 15$20 \%$ [8]. Andersson's research indicates that spinal pain syndrome was the most common reason for reducing the performance of people aged 45 years, and the second most frequent reason for doctor visits. European statistics show that $10 \%-15 \%$ of the reasons for absence at work constitute back pain in the lumbar spine [8]. Due to absenteeism at work and paid benefits, this is one of the serious economic and health problems. It is also estimated that about $60-$ $80 \%$ of Europeans at the age of 30 suffer from back pain syndrome, while in people over 55, this dysfunction affects up to $98 \%$ of the European population [10]. The Fourth European Survey on Working Conditions research shows that Poland is the second largest EU country in terms of the number of professionally active people reporting recurrent pain in the spine, which at the same time allows the problem to be considered significant, and prompts the undertaking of research aimed at identifying intrapersonal risk factors, and supporting the quality of coping with the economic sphere of people experiencing this type of health problems [11].

The style of coping with requirements and expectations and the way of functioning in the situation when financial difficulties occur is determined by many social and cultural mechanisms. At their base, there are always some psychological mechanisms, among which the personality plays a crucial role. However, defining the term personality must be conditioned in theoretical assumptions, and no specific personality definition can be used in a universal way. Therefore, it should be assumed that a person's personality consists of a set of descriptive terms that characterize a person in terms of central dimensions within the applied theory [12].

This study is based on a five-factor personality model (the so-called Big Five), distinguishing the following factors: openness, agreeableness, conscientiousness, extraversion and neuroticism. The validity of this concept has been confirmed in many lexical [14] and psychometric studies [13].

Personality traits determine relatively constant patterns of perception of situation, its cognitive appraisal and emotional response, and manifest themselves especially in difficult situations $[15,16]$. Great importance is attached here to neuroticism and extraversion, which condition the predisposition to experience negative or positive emotions [17, 18]. It is assumed that neuroticism is conducive to experiencing anxiety, irritation and anger in a difficult situation, which leads to the exaggeration of difficulties, and perceiving them in terms of loss or danger [19]. Extraversion, on the other hand, is connected with experiencing positive emotions, an optimistic assessment of the future and a tendency to perceive difficulties as tasks to be challenged. It is also related to the ability to replace difficult or unrealistic goals with new and realistic ones, as well as the ability to seek social support [16]. Similarly, agreeableness, which is characterized by trust and a tendency to cooperate, facilitates the search for social support and influences the experience of positive emotions in social situations. It is also assumed that conscientiousness is a determinant of a locus of control in problem situations. On the other hand, people with a high level of openness show greater readiness to undertake non-standard activities in stressful situations, which may help in overcoming them, but on the other hand, they are characterized by a tendency to take risky actions (e.g. use psychoactive substances) [20]. Among the personality characteristics that affect coping with a difficult situation, emotional stability, coherence, self-esteem, sense of effectiveness and life optimism, are also mentioned $[21,22]$.

It should also be noticed that according to the sociocognitive theory, human behaviour is guided by expectations concerning the situation, the result of the action and selfefficacy. It is assumed that the stronger the beliefs about the sense of self-efficacy, the higher the goals people set, and the stronger their commitment to the intended action, even in the face of difficulties. Often, it is the self-efficacy that determines the choices a person makes, and affects perseverance in action aimed at achieving a specific goal [23].

\section{OBJECTIVE}

The aim of the study was to determine the intrapersonal correlates of the tendency to seek help in the situation of indebtedness in healthy people, and in patients with impaired mobility on the basis of chronic diseases of the musculoskeletal system.

Research problem and hypothesis. With regard to the stated objective of the research, the focus was on answering the question: What are the intrapersonal correlates of the tendency to seek help in a situation of indebtedness depending on health condition?

In response to the research problem posed, it was assumed that the selected intrapsychic features are connected with the tendency to seek help in a situation of indebtedness, and the moderator of the existing relationships is the condition of health (patients with mobility impairment on the basis of chronic musculoskeletal diseases vs. healthy people).

\section{MATERIALS AND METHOD}

The research sample was collected on the basis of intentional choice. It consists of 2 groups - 50 patients with mobility impairment resulting from chronic pathologies of the locomotor system, hospitalized in the Department of General and Neuro-Rehabilitation in the Institute of Rural Health in Lublin, and 50 healthy people who declared that they had not been diagnosed with any psycho-somatic diseases, and who met the criteria of a healthy person included in the definition of the World Health Organization (WHO), that is, they manifested complete well-being at the physical, mental and social level [24]. Patients with impaired mobility resulting from chronic musculoskeletal disorders - diagnosed with Barthel Scale, needed other people's help while performing daily activities. (Min. $=65.00 ;$ Max $=80.00$; $M=75.00 ; S D=10.00)$. The main disease causing the state of physical disability was long-term, advanced multi-joint osteoarthritis affecting spine joints. On the background of internal medicine, the majority of the examined persons suffered from such diseases as hypertension, ischemic heart 
disease, chronic arrhythmias, chronic heart failure I-II in the NYHA scale, insulin-dependent and non-insulin dependent diabetes, and transient cerebral circulatory disorders.

Detailed characteristics of the subjects are presented in Table 1. The average age of patients was 61.27 years $(S D=16.00)$, and of healthy people $-59.95(S D=9.93)$. Both the clinical group and the healthy population were homogenous due to gender. Both hospitalized persons $(\mathrm{M}=1.12, \mathrm{SD}=0.38)$ and healthy subjects $(\mathrm{M}=1.33$, $\mathrm{SD}=0.54)$, on average, had one child. Each group was dominated by married people who had completed secondary education and came from rural areas. The respondents declared that they did not smoke cigarettes and that alcoholic beverages were consumed occasionally.

Table 1. Socio-demographic characteristic of the researched groups

\begin{tabular}{|c|c|c|c|c|c|}
\hline \multirow{3}{*}{ Variables } & & \multicolumn{4}{|c|}{ Goup } \\
\hline & & \multicolumn{2}{|c|}{ patients } & \multicolumn{2}{|c|}{ healthy people } \\
\hline & & $\mathrm{N}$ & $\%$ & $\mathrm{~N}$ & $\%$ \\
\hline \multirow{2}{*}{ Gender } & Female & 25 & 50.0 & 25 & 50.0 \\
\hline & Male & 25 & 50.0 & 25 & 50.0 \\
\hline \multirow{4}{*}{$\begin{array}{l}\text { Marital } \\
\text { status }\end{array}$} & Single & 6 & 12.0 & 10 & 20.0 \\
\hline & Married & 28 & 56.0 & 39 & 78.0 \\
\hline & Divorced & 5 & 10.0 & 1 & 2.0 \\
\hline & Widowed & 11 & 22.0 & 0 & 0.0 \\
\hline \multirow{4}{*}{ Education } & Elementary & 10 & 20.4 & 1 & 2.0 \\
\hline & Vocational & 11 & 22.4 & 2 & 4.0 \\
\hline & Secondary & 17 & 34.7 & 31 & 62.0 \\
\hline & Higher & 11 & 22.4 & 16 & 32.0 \\
\hline \multirow{3}{*}{$\begin{array}{l}\text { Place of } \\
\text { residence }\end{array}$} & Village & 19 & 38.8 & 21 & 42.0 \\
\hline & City up to 100 thousand residents & 16 & 32.7 & 15 & 30.0 \\
\hline & city over 100 thousand residents & 14 & 28.6 & 14 & 28.0 \\
\hline
\end{tabular}

Source: own research results.

The research was carried out using the Barthel Scale by F.I. Mahoney and D. Barthel [25], the NEO-FFI Personality Inventory by P.T. Costa, R.R. McCrae, in the Polish adaptation of B. Zawadzki, J. Strelau, P. Szczepaniak and M. Śliwińska [26], Perceived Stress Scale - PSS-10 (authors: S. Cohen, T. Kamarck \& R. Mermelstein; adaptation: Z. Juczyński, N. Ogińska-Bulik [27], SES M. Rosenberg Self-Esteem Scale in the Polish adaptation by I. Dzwonkowska, K. LachowiczTabaczek and M. Laguna [28], General Self-Efficacy Scale (GSES) by Schwarzer, M. Jerusalem and Z. Juczyński [29], Impulsiveness Inventory (IVE) by H. J. Eysenck and S.B.G. Eysenck in the Polish adaptation by A. Jaworowska [30], and the Psychosocial Aspects of Debt Questionnaire (APSZ).

The Barthel Scale is a tool designed to assess the patient's level of fitness and independence, as well as the level of care demand that is associated with them. The questionnaire includes 10 everyday activities: eating meals; moving from bed to chair and back, sitting down; maintaining personal hygiene; use of the toilet; moving on flat surfaces; climbing and going down stairs; dressing and undressing, and controlling physiological activities. The potential range of the assessment ranges from $0-100$ points, with a score from $0-20$ points indicates total reliance, $21-80$ points mean that to a certain extent the patient requires the care of other people, and results from 81-100 points suggests that the subject can function alone using only a small amount of help. A score of $0-40$ indicates the need to qualify the patient for long-term care, because of requiring constant help [25].

The NEO-FFI inventory is the only tool in Poland allowing for the assessment of personality features according to a 5-factor personality model. The tool is based on the theoretical model by P. Costa and R. McCrae of the socalled Big Five, which assumes that 5 major dimensions can be distinguished in the human personality: Neuroticism, Extraversion, Openness to Experience, Agreeableness, and Conscientiousness. The inventory consists of 60 items and is intended for men and women over 15 years of age [26].

The PSS-10 scale was created by S. Coen, T. Kamarck and R. Mermelstein in 1983. This tool enables assessment of the intensity of stress associated with life situation over the past month. The scale consists of 10 questions regarding various subjective feelings related to personal problems and events, behaviours and coping methods. The tool is intended for research purposes and can also be used in psychological practice - in screening, prophylactic purposes, as well as in the assessment of the effectiveness of therapeutic interactions. The PSS-10 questionnaire can be used in individual and group research [27].

The SES scale is the most commonly used tool for selfesteem measurement and can be used in studies of adolescents and adults. The theoretical basis of the questionnaire is the definition of self-esteem according to M. Rosenberg, who understands it as a positive or negative attitude towards the self, and thus a kind of global self-assessment. SES consists of 10 statements. Subject answers on a 4-point scale depending on the degree to which he or she agrees with the statements. [28].

The GSE Scale was created by R. Schwartzer and M. Jerusalem in 1992 to measure the general belief of a person about the effectiveness of dealing with difficult situations and obstacles. The questionnaire consists of 10 questions that form one scale. The GSES questionnaire can be administered individually or in groups, and healthy as well as sick adults can fill in the questionnaire [29].

The IVE questionnaire was constructed to assess 3 personality traits: impulsiveness, venturesomeness, and empathy. It consists of 54 questions to be answered with Yes or No. It can be administered in research as well as in e individual diagnosis [30].

The APSZ survey was constructed for the needs of the presented research and concerns various social situations related to incurring financial liabilities. It consists of 17 questions concerning subjects' current financial situation, current or past financial obligations, a self-description of the so-called economy, conviction about having basic knowledge concerning financial management and reliability in repayment of ones' financial obligations. When answering the 8 questions, the subjects choose the correct answer, and in nine items they give answers on the 5-point Likert scale.

The research was carried out in 2018 after having obtained the consent of the Bioethical Commission of the Witold Chodźki Institute of Rural Medicine in Lublin. The research was voluntary, individual and anonymous. It was conducted in accordance with the Declaration of Helsinki of 2013.

The subjects were informed about the purpose and course of the research, the confidentiality of the collected data and they consented in writing to participate in the research. 
Statistical calculations were performed using the IBM SPSS 24 software. The characteristics of the researched sample were based on the calculation of the percentage distribution of the qualitative data frequency, and descriptive statistics of quantitative variables. The predictive analytics was performed using stepwise regression. In the study, the boundary point of committing type I error was 0.05 .

\section{RESULTS}

Results of the performed predictive analysis in the group of patients with impaired mobility resulting from chronic diseases of the locomotor system are presented in Table 2 . In the group of patients with mobility impairment due to the chronic locomotor system disease, a model was constructed consisting of one step, in which one predictor explaining 38\% $\left(\mathrm{R}^{2}\right.$ adjusted $\left.=0.38\right)$ variance of the variable tendency to seek help in the case of indebtedness was introduced.

Table 2. Intrapersonal correlates of the tendency to seek help in the situation of indebtedness in the group of patients with impaired mobility resulting from chronic diseases of the locomotor system

\begin{tabular}{lccccccccc}
\hline \multirow{2}{*}{ Model } & \multicolumn{3}{c}{ Measures of model fit } & \multicolumn{6}{c}{ Regression weights for predictors } \\
\cline { 2 - 9 } & $R^{2}$ adjusted & $F$ & $p$ & $B$ & $S E$ & $\beta$ & $t$ & $P$ \\
\hline Step 1 & & & & & & & & \\
\hline Extraversion & 0.38 & 30.99 & 0.001 & 0.07 & 0.01 & 0.62 & 5.57 & 0.001 \\
\hline
\end{tabular}

Source: own research results

The constructed model fits the data, F (1.49)=30.99; $\mathrm{p}=0.001)$ and indicates that the leading predictor of the analyzed variable is extraversion $(\beta=0.62 ; p=0.001)$. The relationship between the introduced predictor and the explained variable is directly proportional, which means that in the group of patients with impaired mobility resulting from chronic diseases of the locomotor system, the main determinant of the tendency to seek help in the situation of indebtedness is vital optimism, cordiality, willingness to look for new experiences, and leading an active lifestyle.

Results of the prediction analysis carried out in the healthy group are presented in Table 3 . In the healthy group, the calculations performed allowed development of a model consisting of 5 steps in which 5 predictors explaining $27 \%$ of the variance of the variable tendency to seek help in case of debt were introduced. In the first step, the intensity of stress was introduced as an explanatory variable. The model turned out to fit the data and explained $7.0 \%\left(\mathrm{R}^{2}\right.$ adjusted $\left.=0.07\right)$ of the variance of the dependent variable $F(1.49)=7.74 ; p=0.007$. In the second step, neuroticism was introduced to the model. It fitted the data well and explained $10.0 \%\left(\mathrm{R}^{2}\right.$ adjusted $\left.=0.10\right)$ of the explanatory variable, $F(2.48)=6.27 ; p=0.003$. In the third step, self-esteem was introduced to the model. It fitted the data well and explained $18.0 \%\left(\mathrm{R}^{2}\right.$ adjusted $\left.=0.18\right)$ of the explanatory variable $F(3.47)=7.45 ; p=0.001$. In the fourth step, the model was supplemented with self-efficacy. It fitted the data well and explained $22.0 \%\left(\mathrm{R}^{2}\right.$ adjusted $\left.=0.22\right)$ of the explanatory variable $F(4.46=7.38 ; p=0.001)$. in the fifth step, empathy was introduced to the model. It also fitted the data well and explained $27.0 \%\left(\mathrm{R}^{2}\right.$ adjusted $\left.=0.27\right)$ of the explanatory variable, $F(5.45)=7.73 ; p=0.001$.

The developed model revealed that in the healthy group, significant predictors of the tendency to seek help in the
Table 3. Intrapersonal correlates of the tendency to seek help in the situation of indebtedness in the group of healthy people

\begin{tabular}{|c|c|c|c|c|c|c|c|c|}
\hline \multirow{2}{*}{ Model } & \multicolumn{3}{|c|}{ Measures of model fit } & \multicolumn{5}{|c|}{ Regression weights for predictors } \\
\hline & $R^{2}$ adjusted & $F$ & $p$ & $B$ & SE & $\beta$ & $t$ & $p$ \\
\hline \multicolumn{9}{|l|}{ Step 1} \\
\hline Stress & 0.07 & 7.74 & 0.007 & -0.06 & 0.02 & -0.28 & 2.78 & 0.007 \\
\hline \multicolumn{9}{|l|}{ Step 2} \\
\hline Stress & \multirow{2}{*}{0.10} & \multirow{2}{*}{6.27} & \multirow{2}{*}{0.03} & -0.08 & 0.02 & -0.41 & 3.52 & 0.001 \\
\hline Neuroticism & & & & -0.05 & 0.02 & -0.25 & 2.12 & 0.037 \\
\hline \multicolumn{9}{|l|}{ Step 3} \\
\hline Stress & \multirow{3}{*}{0.18} & \multirow{3}{*}{7.45} & \multirow{3}{*}{0.001} & -0.07 & 0.02 & -0.37 & 3.28 & 0.001 \\
\hline Neuroticism & & & & -0.08 & 0.03 & -0.41 & 3.28 & 0.001 \\
\hline Self-esteem & & & & 0.09 & 0.03 & 0.34 & 2.95 & 0.04 \\
\hline \multicolumn{9}{|l|}{ Step 4} \\
\hline Stress & \multirow{4}{*}{0.22} & \multirow{4}{*}{7.38} & \multirow{4}{*}{0.001} & -0.09 & 0.02 & -0.46 & 4.01 & 0.001 \\
\hline Neuroticism & & & & -0.08 & 0.02 & -0.40 & 3.33 & 0.001 \\
\hline Self-esteem & & & & 0.13 & 0.03 & 0.45 & 3.73 & 0.001 \\
\hline Self-efficacy & & & & 0.08 & 0.03 & 0.29 & 2.43 & 0.017 \\
\hline \multicolumn{9}{|l|}{ Step 5} \\
\hline Stress & \multirow{5}{*}{0.27} & \multirow{5}{*}{7.73} & \multirow{5}{*}{0.001} & -0.08 & 0.02 & -0.39 & 3.43 & 0.001 \\
\hline Neuroticism & & & & -0.09 & 0.02 & -0.46 & 3.87 & 0.001 \\
\hline Self-esteem & & & & 0.14 & 0.03 & 0.50 & 4.28 & 0.001 \\
\hline Self-efficacy & & & & 0.09 & 0.03 & 0.34 & 2.95 & 0.004 \\
\hline Empathy & & & & 0.09 & 0.03 & 0.27 & 2.66 & 0.009 \\
\hline
\end{tabular}

Source: own research results

situation of debt were the intensity of perceived stress, $\beta=-0.39 ; p=0.001$, neuroticism, $\beta=-0.46 ; p=0.001$, selfesteem, $\beta=0.50 ; p=0.001$, self-efficacy, $\beta=0.34 ; p=0.001$ and empathy, $\beta=0.27 ; \mathrm{p}=0.001$.

The relationships between the intensity of experienced stress and neuroticism and the explained variable were inversely proportional, while the relationship between self-esteem, self-efficacy and empathy and the dependent variable - positive, which indicates that in the group of healthy people with the increase in the level of perceived tension and emotional hyper-reactivity, the tendency to seek help in a situation of debt was decreasing. On the other hand, as the self-esteem, the belief in the possibility of achieving the goal and empathy increased together with the tendency to seek help in the event of financial difficulties.

\section{DISCUSSION}

Statistical analyzes indicated extraversion as the leading, positively correlated indicator of readiness to search for help in getting out of indebtedness in people suffering from chronic musculoskeletal disorders. Extraversion, apart from an optimistic approach to the future, willingness to take up activity, was an important factor in helping the adaptation of the individual to new life situations. For the studied clinical group, the high level of extraversion, was simultaneously an important factor protecting them in financial problems associated with earlier indebtedness $[31,32,33]$.

In the control group, healthy people characterized by higher level of anxiety, irritability, emotional lability, excessive criticism in assessing their own behaviors, belonged 
to the group who tried to solve financial problems on their own, irrespective of the effectiveness of the actions taken $[32,33,34,35]$.

An important observation resulting from the obtained results is the fact that the factors that protect this group of people are: high level of self-esteem, self-efficacy and empathy. Therefore, the belief in one's own worth, abilities, self-confidence, and the ability to take actions that bring the planned effect - in the case of experiencing financial difficulties also favour the perception of others as a source of help, and constitute an important factor in solving problems. Undoubtedly, a higher level of empathy plays a crucial role here- indicating the ability to adopt a point of view and understanding of others, looking at a given situation from another person's perspective, which at this moment could be helpful in solving financial problems $[36,37,38]$.

The practical indication resulting from the conducted study is the need to pay attention to people suffering from diseases of the motor system, experiencing financial difficulties and characterized by psychological introversion. This personality trait itself indicates the withdrawal from interpersonal relations, lack of self-confidence in social situations, and unwillingness to undertake activities. However, when looking for an effective solution to financial problems, most often related to debt, high costs incurred in connection with treatment or rehabilitation, the introvert will be more reluctant to ask for help from others. As long as it may mean caution before entering into risky obligations, it may act as a specific protective factor. Nevertheless, extending the duration of the indebtedness and remaining alone with unsolved problems can cause growing financial and health problems, both somatic and mental [39, 40, 41, 42, 43].

Although the hypothesis has been confirmed in relation to selected personality traits, it should be mentioned that the test results cannot be generalized. Dependencies (and their absence) were checked on a small group of people. To what extent the results could represent a larger population should be the subject of further research.

\section{CONCLUSIONS}

1. The analyzes carried out showed that the particular dimensions of intrapersonal functioning are related to the tendency to seek help in the situation of indebtedness, and the state of health is the moderator of the existing relationships.

2. In the group of patients with impaired mobility linked to chronic pathologies of the locomotor system, extroversion is a factor conducive to seeking help in the case of indebtedness.

3. In the group of healthy people, the factors that favour the search for help in the situation of indebtedness are selfesteem, self-efficacy and empathy, while the factors that weaken the motivation to undertake such activities are the intensification of perceived stress and neuroticism.

4. The results obtained indicate the need to take into account the specificity of the health situation of participants in psycho-preventive programmes aimed at supporting people who experience difficulties in dealing with the repayment of their financial obligations.

\section{REFERENCES}

1. Senthelal S, Thomas MA. Arthritis. Treasure Island (FL) StatPearls Publishing, 2018.

2. Stanisławska-Biernat E, Filipowicz-Sosnowska A. [Treatment of osteoarthritis]. Przew Lek GPs. 2005; 7(11): 62-70. (in Polish)

3. O'Neill TW, Felson DT. Mechanisms of Osteoarthritis (OA) Pain. Curr Osteoporos Rep. 2018. doi: 10.1007/s11914-018-0477-1.

4. Segal NA, Glass NA. Is quadriceps muscle weakness a risk factor for incident or progressive knee osteoarthritis? Phys Sportsmed. 2011; 39(4): 44-50.

5. Semanik PA, Chang RW, Dunlop DD. Aerobic activity in prevention and symptom control of osteoarthritis. PM R. 2012; 4(5 Suppl): S37-44.

6. Tuszyńska-Bogucka W, Saran T, Jurkowska B, Dziaduch W. Psychosocial generalised resistance resources and clinical indicators of patients suffering from osteoarthritis at the Institute of Rural Health in Lublin, Poland. Ann Agric Environ Med. 2015; 22(2): 380-4.

7. Hoy D, Brooks P, Blyth F, Buchbinder R. The Epidemiology of low back pain. Best Pract Res Clin Rheumatol. 2010; 24(6): 769-81.

8. Andersson GBJ. Epidemiology of low back pain. Acta Orthop Scand. 1998; 69(sup281): 28-31.

9. Wojtczak A. [Public health-a challenge for 21st century health systems]. Warsaw. PZWL, 2017. (in Polish)

10. Dwornik M, Białoszewski D, Kiebzak W, Lyp M. The correlation of selected physical examination findings and the efficacy of physiotherapy for chronic lumbosacral pain. Ortop Traumatol Rehabil. 2007; 9(3): 297-309.

11. Parent-Thirion A, European Foundation for the Improvement of Living and Working Conditions. Fourth European working conditions survey. Luxembourg Office for Offical Publ. of the European Communities, 2007.

12. Hall CS, Linzey G, Campbell JB. [Theories of personality]. Warszawa, PWN, 2006. (in Polish).

13. McCrae RR, Costa PT. A five-factor theory of personality. In: John OP, Robins RW, Pervin LA, editors. Handbook of personality: Theory and research. Guilford, New York; 2008. p. 159-181.

14. Goldberg LR. The development of markers for the Big-Five factor structure. Psychological Assessment. 1992; 4: 26-42.

15. Costa PT, McCrae RR. Personality in Adulthood. Kraków WAM, 2005.

16. Costa PT, McCrae RR. Influence of extraversion and neuroticism on subjective well-being: Happy and unhappy people. J Personality Soc Psychol. 1980; 38: 668-678.

17. Watson D, Clark LA. Negative affectivity: the disposition to experience negative affective states. Psychological Bulletin. 1984; 96: 465-490.

18. Makowska H, Poprawa R. [Stress coping strategies in health development]. In: Dolińska-Zygmunt G, editor. [An introduction to health psychology]. Wrocław University, Wrocław; 2001. p. 71-102.

19. Watson D, Pennebaker JW. Health complaints, stress, and distress: exploring the central role of negative affectivity. Psychol Rev. 1989; 96: 234-254.

20. Bogg T, Roberts BW. Conscientiousness and health-related behaviors: a metaanalysis of the leading behavioral contributors to mortality. Psychological Bulletin. 2004; 130: 887-919.

21. Heszen-Niejodek I. Emotions: cognitive appraisal and coping strategies.. In: Heszen-Niejodek I, editor. [Theoretical and clinical aspects of coping with psychological stress]. Association of Psychology and Architecture, Poznań; 2002. p. 174-197. (in Polish).

22. Ogińska-Bulik, N. [Stress and coping]. In: Bielawska-Batorowicz E, editor, [Introduction to psychology for economists]. PWE, Warszawa; 2012. (in Polish).

23. Juczyński Z. (2000), [Self-efficacy: theory and i measurement]. Acta Universitatis Lodziensis Folia Psychologica. 2000; 4: 11-23. (in Polish).

24. http://www.who.int/.[access 25.11.2018].

25. Mahoney FI, Barthel, D. Functional Evaluation: The Barthel Index. Md State Med J. 1965; 14: 61-65.

26. Zawadzki B, Strelau J, Szczepaniak P, Śliwińska M. NEO-FFI. [Personality Inventory Paul. Costa Jr and Robart R. McCrae. Polish adaptation]. Warsaw Psychological Test Laboratory of the Polish Psychological Association, 2010. (in Polish).

27. Juczyński Z, Ogińska-Bulik N. [Assessment and Diagnostic Instruments for Health Psychology Promotion]. Warsaw Psychological Test Laboratory of the Polish Psychological Association, 2009. (in Polish).

28. Dzwonkowska I, Lachowicz-Tabaczak K, Łaguna M. [SES - selfassessment and its measurement. Polish adaptation of the SES M. Rosenberg scale]. Warszawa Pracownia Testów Psychologicznych, 2008. (in Polish). 
29. Juczyński Z. [Assessment and Diagnostic Instruments for Health Psychology Promotion]. Warsaw Psychological Test Laboratory of the Polish Psychological Association, 2009. (in Polish).

30. Jaworowska A, [IVE. Impulsiveness Inventory. Impulsiveness. Venturesomeness Empathy]. Warsaw Psychological Test Laboratory of the Polish Psychological Association, 2011. (in Polish).

31. Brown S, Taylor K. Household Finances and the "Big Five".Great Britain Sheffield University of Sheffield, 2011.

32. Caliendo M, Fossen F, Kritikos A. Personality Characteristics and the Decision to Become and Stay Self-Employed. Germany Berlin DIW, 2011.

33. Borghans LAL, Duckworth AL, Heckman JJ, terWeel B. The Economics and Psychology of Personality Traits. J Human Res. 2008; 43(4): 972 1059.

34. Elbogen EB, Tiegreen J, Vaughan C, Bradford D. W. Money management, mental health, and psychiatric disability: A recovery-oriented model for improving financial skills. Psych Rehab J. 2011; 34(3): 223-231.

35. Kim J, Garman ET, Sorhaindo B. Relationships Among Credit Counseling Clients' Financial Well-Being. Financial Behaviors, Financial Stress Events and Health. Financial Counselling and Planning. 2003; 14: 75-87.
36. Balmer N, Pleasence P, Buck A, Walker H. Worried Sick: The Experience of Debt Problems and their Relationship with Health, Illness and Disability. Social Policy and Society. 2006; 5(1): 39-51.

37. Allmark P, Machaczek K. Financial capability, health and disability. BMC Public Health. 2015; 15: 243.

38. Howlett E, Kees J, Kemp E. The role of self-regulation, future orientation, and financial knowledge in long-term financial decisions. J Cons Aff. 2008; 42: 223-242.

39. Burke-Miller JK, Swarbrick MA, Carter TM, Jonikas JA, Zipple AM, Fraser VV, Cook JA. Promoting self-determination and financial security through innovative asset building approaches. Psych Rehab J. 2010; 34: 104-112.

40. Jiménez-Solomon O G, Méndez-Bustos P, Swarbrick M, Díaz S, Silva S, Kelley M, Lewis-Fernández R. Peer-supported economic empowerment: A financial wellness intervention framework for people with psychiatric disabilities. Psych Rehab J. 2016; 39: 222-233.

41. Delaney L, Harmon C, Ryan M. The role of noncognitive traits in undergraduate study behaviours. Econ Edu Rev. 2013; 32: 181-195.

42. Daly M, Delaney L, McManus S. Risk Attitudes as an Independent. Predictor of Debt. Dublin UCD Geary Institute Discussion Paper Series, 2010.

43. Agarwal S, Mazumder B. Cognitive abilities and household financial decision making. Am Econ J: App Econ. 2013; 5(1): 193-207.

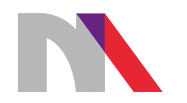

Ministry of Science and Higher Education

Republic of Poland

Generation of the DOI (Digital Object Identifier) - task financed under the agreement No. 618/P-DUN/2019 by the Minister of Science and Higher Education 